\title{
Estratégias de relações públicas para as organizações em tempos de mídias sociais digitais
}

Public relations strategies for organizations

in an era of digital social media

Estrategias de relaciones públicas para las organizaciones en tiempos de medios sociales digitales

Bianca Marder Dreyer

- Doutoranda do Programa de Pós-Graduação em Ciências da Comunicação da Escola de Comunicações e Artes da Universidade de São Paulo (ECA-USP)

- Mestre em Ciências da Comunicação pela ECA-USP, na linha de pesquisa "Comunicação e ambiências em redes digitais"

- Bacharel em Comunicação Social, com habilitação em Relações Públicas, pela ECA-USP

- Professora de Relações Públicas na Faculdade Cásper Líbero (Facásper)

- Assistente acadêmica do Curso de Pós-Graduação Lato Sensu de Gestão Integrada da Comunicação Digital em Ambientes Corporativos (Digicorp) da ECA-USP

- Integra grupo de pesquisa "Comunicação e mídias digitais (Com+)", da ECA-USP

- E-mail: biancamdreyer@gmail.com 


\section{Resumo}

Este é um artigo teórico que tem como objetivo apresentar as relações públicas no contexto digital. Para isso, mostraremos a evolução dessa atividade, indicando a relação determinante com a web e, para exemplificar, descreveremos dois modelos de comunicação contemporâneos. Esse percurso nos fornecerá indícios de quais são as estratégias indicadas para a gestão da comunicação em tempos de mídias sociais digitais. A resposta nos levará à possibilidade de reflexão sobre uma futura proposta de modelo de comunicação na contemporaneidade.

PALAVRAS-CHAVE:RELAÇÕES PÚBLICAS • COMUNICAÇÃO DIGITAL • COMUNICAÇÃO ORGANIZACIONAL • MÍDIAS SOCIAIS DIGITAIS.

\section{Abstract}

This theoretical article aims at presenting public relations in the digital context. For this we will show the evolution of the activity, showing the determining relationship with the web and, to illustrate, we will describe two contemporary communication models. This route will provide us with the clues on the recommended strategies for communication management in an era of digital social media. The answer will lead us to the possibility of reflection on a future proposal for a contemporary communication model.

KEYWORDS: PUBLIC RELATIONS • DIGITAL COMMUNICATION • ORGANIZATIONAL COMMUNICATION • MODELS • DIGITAL SOCIAL MEDIA.

\section{Resumen}

Esteesun artículo teórico que tiene como objetivo presentar las relaciones públicas en el contexto digital. Para eso, mostraremos la evolución de esa actividad, mencionando la relación determinante con la weby, para ejemplificar, serán descritos dos modelos de comunicación contemporáneos. Ese trayecto nos proporcionará indicios de cuáles son las estrategias recomendadas para la gestión de la comunicación en tiempos de medios sociales digitales. La respuesta nos conducirá a la posibilidad de reflexión sobre una futura propuesta de modelo de comunicación en la contemporaneidad. 


\title{
ANO $12 \cdot$ NÚMERO $22 \cdot 1^{10}$ sem. $2015 \cdot$ ORGANICOM \\ ESTRATÉGIAS DE RELAÇÕES PÚBLICAS PARA AS ORGANIZAÇÕES EM TEMPOS DE MÍDIAS SOCIAIS DIGITAIS
}

\begin{abstract}
$\Lambda$ atividade de relações públicas vem evoluindo e ampliando sua atuação nas organizações, principalmente após a 1 chegada das tecnologias de informação e (TICS), que provocam e, de certa forma, impõem novas estratégias aos profissionais de comunicação. Dessa forma, pensar a comunicação de uma empresa na contemporaneidade pressupõe compreender a evolução e as características das diferentes fases da web que vem, cada vez mais, configurando outras formas de relações, como aquelas que se dão através das plataformas de mídia social digital e que são dotadas de interação, simetria, integração, convergência, não linearidade, entre muitas outras características.
\end{abstract}

As consequências de tal evolução da web para a gestão da comunicação nas empresas também provocam o repensar de modelos de comunicação e de relações públicas ou ainda proporcionam o amálgama desses modelos por parte das empresas em relação a seus públicos. Pois, se, por um lado, as empresas deixam de ter a primazia do discurso, por outro, os indivíduos se tornam protagonistas da comunicação. E é justamente esse protagonismo que, na maior parte das vezes, é manifestado por meio do uso das plataformas de mídias sociais digitais, ou seja, um protagonismo que, pela sua forma de acontecer, também configura aquilo que Manuel Castells (2011, p. 566) chamou de arquiteturas das relações na sociedade em rede.

Aos poucos, as organizações estão se dando conta do potencial das plataformas de mídias sociais digitais. No entanto, apenas ingressar nessas plataformas e se portar como um observador ou um publicador de informações, mesmo que com mensagens diárias e bem criativas, não é suficiente. Os públicos esperam mais das empresas e, se há ainda indivíduos que nada esperam, mesmo assim é importante que as empresas se posicionem para que sejam percebidas de forma positiva.

Diante desse contexto, este artigo tem como objetivo apresentar as relações públicas no contexto digital. Para isso, a parte I mostrará a evolução dessa atividade até chegarmos ao que entendemos por relações públicas digitais, indicando a relação determinante entre tal atividade e a web. Será também descrita a evolução da web 1.0 até a 4.0 e analisada a atividade de relações públicas frente a esse cenário. A parte II descreverá dois modelos de comunicação contemporâneos para exemplificar possíveis processos de comunicação nas empresas. Esse percurso nos fornecerá indícios para levantar as estratégias indicadas para a gestão da comunicação em tempos de mídias sociais digitais mencionadas no primeiro tópico. Por fim, refletiremos a respeito de uma proposta de modelo de comunicação na contemporaneidade.

Este é um estudo teórico que discorre sobre os principais temas e autores que pesquisam a atividade de relações públicas no contexto digital e a comunicação digital nas organizações. Uma vez que o objeto de estudo deste artigo apresenta relação direta com o ambiente digital e as empresas, buscamos um referencial teórico que contempla pesquisadores acadêmicos e estudiosos do mercado também.

\section{O PERCURSO PARA ENTENDERMOS AS RELAÇÕES PÚBLICAS NO CONTEXTO DIGITAL}

Neste primeiro tópico mesmo que brevemente, apresentamos a diferença entre internet e web. A internet foi usada pela primeira vez em 1969 e se difundiu rapidamente vinte anos mais tarde, segundo Castells (2011, p. IX). De acordo com 0 mesmo autor, a criação e o desenvolvimento da internet foram consequência de uma fusão de estratégica militar, grande cooperação científica, iniciativa tecnológica e inovação contracultural (Castells, 2011, p. 82). A world wide web (www) ou, simplesmente, web surgiu como um avanço da internet, possibilitando a muito mais pessoas o acesso a essa tecnologia. Considerada, na época, como um novo aplicativo, a web foi inventada na Europa, em 1990, por um grupo de pesquisadores chefiados por Tim Berners Lee (Castells, 2011, p. 88). 


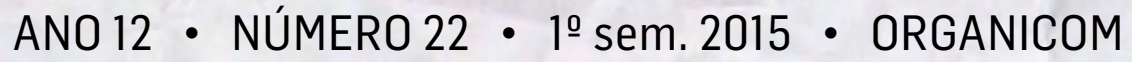 \\ ESTRATÉGIAS DE RELAÇÕES PÚBLICAS PARA AS ORGANIZAÇÕES \\ EM TEMPOS DE MÍDIAS SOCIAIS DIGITAIS}

\section{Evolução da internet e da web}

A web 1.0 inicia-se com o surgimento da própria www nos anos 1990 e constituiu a primeira era da web. De acordo com 0 senso coletivo da Wikipédia', a web 1.0 é considerada estática, pois todo o conteúdo da página é somente para leitura. Nessa fase, também não existia a interatividade do usuário e somente o webmaster ou o programador podia realizar alterações ou atualizações da página.

Para entendermos sua aplicabilidade, Elizabeth Saad Corrêa (2003, p. 155) descreve o cenário 1.0 de presença digital de três formas: (a) características técnicas: multimedialidade, hipermedialidade e interatividade; (b) ferramentas de comunicação: websites, jornais e revistas on-line, email, entre outras; e (c) formas de participação do usuário: fale conosco, fóruns, batepapos, entre outras.

Embora considerada estática, a web 1.0 apresenta possibilidades restritas de interação com os usuários a partir do momento em que é possível ocorrer contato, via rede, com a empresa. Como explica Beth Saad (2003, p. 155), no cenário 1.0, uma vez que o controle do conteúdo e das relações permanece nas mãos do emissor, a maioria de suas propostas de interatividade e diálogos com o usuário não passa de ações que simulam a participação.

A evolução da fase inicial da web para a chamada web 2.0 é justamente a nova possibilidade de interação. 0 termo web 2.0, de acordo com a mesma autora (Saad, 2003, p. 148), surgiu em 2004. A principal característica dessa fase é a interação proporcionada pelas inúmeras plataformas de comunicação que promovem o diálogo em tempo real. Na tentativa de concretizar essa mudança, podemos dizer que, com a web 2.0, literalmente, surgiu mais um espaço para a comunicação, um espaço virtual, um local repleto de desafios para a comunicação organizacional. Para Saad (2003, p. 149), esses desafios se justificam, pois a web 2.0 potencializa a ação do usurário na rede por meio da oferta, quase sempre gratuita, de ferramentas que permitem a expressão e o compartilhamento com outros usuários.

A web 2.0 foi fundamental para que uma "nova classe" de público surgisse: o público das redes, o indivíduo conectado, as audiências (Jenkins, 2009) ou o usuário-mídia (Terra, 2010), provocando nas organizações a necessidade de pensar em outro formato de comunicação que contemple o digital. Para as organizações, a web 2.0 representa um compartilhamento do poder da informação. Para os indivíduos conectados, representa o papel de "comunicador autônomo" ou ainda "protagonista da comunicação".

Por fim, Saad apresenta o cenário 2.0 de presença digital acrescentando os seguintes elementos ao cenário 1.0: (a) características técnicas: conteúdo gerado pelo usuário, compartilhamentos e diálogos; (b) instrumentos e ferramentas de comunicação; e (c) formas de participação do usuário: Facebook, Twitter, blogs, entre muitos outros exemplos de plataformas de mídias sociais digitais. Portanto, fica evidente o aumento das possibilidades de comunicação e, principalmente, de interação quando analisamos o cenário 2.0.

A web 3.0 aprimora profundamente as eras anteriores proporcionando um refinamento dos dados disponíveis para pesquisa e interação, sendo a web semântica² um dos pontos centrais dessa fase. Lucia Santaella (2010, p. 72), quando escreveu a respeito das linhas de frente do ciberespaço e de seus híbridos, contextualizou a web 3.0 como uma das várias linhas de frente do então atual estado da arte. Segundo a autora, "a web 2.0 e suas plataformas participativas (...) já começam a

1 WIKIPÉDIA. Web 1.0. Disponível em: <http://pt.wikipedia.org/wiki/World_Wide_Web\#Web_1.0>. Acesso em: 22 mar. 2014.

2 De acordo com Berners-Lee, Hendler e Lassila (2001, apud Saad e Bertocchi, 2012, p. 126), a web semântica não é uma rede separada, mas uma extensão da atual, na qual a informação recebe um melhor significado, os computadores são mais bem programados e as pessoas trabalham em colaboração. 


\section{ANO 12 • NÚMERO $22 \cdot 1^{10}$ sem. 2015 - ORGANICOM \\ ESTRATÉGIAS DE RELAÇÕES PÚBLICAS PARA AS ORGANIZAÇÕES EM TEMPOS DE MÍDIAS SOCIAIS DIGITAIS}

se imiscuir com a 3.0, a web semântica aliada à inteligência artificial por meio da qual a rede deve organizar e fazer uso ainda mais inteligente do conhecimento já disponibilizado on-line". Para Saad e Bertocchi (2013, p. 141), a web semântica, os algoritmos e os apps são os elementos técnicos fundantes para a existência da recente camada técnico-informativa, também conhecida como web 3.0.

Por fim, a web 4.0 parece ser a fase em que assistiremos a uma revolução de tudo aquilo que vivenciamos até então e que nos faz acreditar que a nossa relação com máquinas e objetos será radicalmente potencializada pelas infinitas possibilidades de interação. É a fase da comunicação das coisas (Lemos, 2014), da ubiquidade e de tudo aquilo que possibilita o intercâmbio entre o mundo físico e o digital.

No entanto, embora cada fase da web apresente suas características marcantes, tais fases não são exatamente cronológicas. Elas convergem e se sobrepõem. Portanto, a atividade de relações públicas praticada nesses contextos também converge e se sobrepõe, como veremos a seguir.

\section{A atividade de relações públicas nas diferentes fases da web}

Identificamos as "relações públicas 1.0" quando, por exemplo, analisamos o cenário 1.0 de presença digital descrito por Saad anteriormente. As empresas transmitiam e ainda transmitem suas mensagens em websites, jornais e revistas online, e-mails, newsletters, além de utilizarem intranet para os funcionários e oferecerem um serviço de "fale conosco" para seus públicos. Portanto, nesse período, o uso das ferramentas, bem como o conteúdo das mensagens acompanhavam as características da web 1.0, ou seja, os profissionais de comunicação estavam diante de uma rede estática, sem interação com o usuário e sob o domínio da empresa, considerada aqui o emissor das mensagens.

Dessa forma, o profissional de relações públicas exercia sua atividade num "contexto tradicional de comunicação", ou seja, em um ambiente no qual os públicos ainda não compartilhavam o espaço comunicacional com as empresas e também não tinham autonomia para se expressarem, portanto, com o uso de meios de comunicação de massa e impressos em sua maioria. Um contexto que, mesmo sendo de comunicação tradicional, evoluiu para os meios eletrônicos e depois para os digitais, mas, ainda assim, não afetava a estrutura das estratégias de comunicação, pois o poder do uso dos meios e das mensagens ainda era das organizações e a participação dos públicos se dava pontualmente em canais como "fale conosco" e e-mails, ou seja, canais de domínio das empresas.

Portanto, embora a atividade de relações públicas seja bem mais antiga que a web 1.0, suas práticas também evoluíram com a chegada desse ambiente pela grandeza de possibilidades comunicacionais que ele oferece. Por esse motivo, fala-se em "relações públicas 1.0", ou "rp 2.0", talvez como o primeiro passo da atividade rumo aos horizontes digitais e contemporâneos. De acordo com Brian Solis e Deirdre Breakenridge (2009, p. xvii), o termo rp 2.0 surgiu quando Solis, na segunda metade da década de 1990, observou uma mudança nas relações públicas, que ele chamou de rp 2.0, em reconhecimento ao impacto que a web teria nas relações públicas e como a indústria da comunicação seria forçada a ter que se conectar com seus públicos ao mesmo tempo em que continuava trabalhando no antigo formato. Portanto, o termo "relações públicas 2.0" nasceu aproximadamente em 1999, bem antes da web 2.0, e foi inspirado pelos primeiros sinais da mudança na mídia durante a ascensão da web 2.0.

Essas mudanças na mídia são aquelas às quais nos referimos anteriormente, ou seja, são novas possibilidades de interação que surgiram com a evolução da fase inicial da web para a chamada 2.0. Nesse sentido, Terra (2010, p. 138), diz que relações públicas 2.0 significa agregar às táticas tradicionais de divulgação conteúdos como vídeos, áudios, fotos, imagens e links que possam ser aproveitados de forma diferente, além de gerir e olhar estrategicamente para canais que permitem a participação de usuários. 


\section{ANO $12 \cdot$ NÚMERO $22 \cdot 1^{10}$ sem. $2015 \cdot$ ORGANICOM \\ ESTRATÉGIAS DE RELAÇÕES PÚBLICAS PARA AS ORGANIZAÇÕES EM TEMPOS DE MÍDIAS SOCIAIS DIGITAIS}

Podemos dizer que a web 2.0 surgiu com uma avalanche de oportunidades para que as empresas possam evoluir no relacionamento com seus públicos e também para que a atividade de relações públicas, que tem em sua essência 0 relacionamento entre organizações e públicos, possa se tornar ainda mais estratégica para as empresas. De acordo com a mesma autora (Terra, 2010, p. 138), a evolução dos relacionamentos organização-públicos passa pelas relações públicas 2.0 e se configura como evolução do conceito tradicional. No entanto, o cerne das relações públicas sempre foi e será o diálogo e a via de mão dupla, conceitos absolutamente conectados com as mídias sociais e com a internet 2 e 3.0 .

Na tentativa de interagir com os públicos, inúmeras empresas estão fazendo uso de plataformas de comunicação digital como Facebook, Twitter, Youtube, Instagram, WhatsApp, entre outras pertinentes à fase 2.0. No entanto, o nível de interação das empresas vai variar de empresa para empresa, conforme a cultura, os gestores e o segmento de cada uma.

Diana Popova (2012, p. 161) explica que o interesse nas mídias sociais, demonstrado pelos profissionais de relações públicas e por pessoas das mais diversas áreas, não significa que se deve abandonar tudo que veio antes da web 2.0 focando apenas na mídia social. Existe uma grande parte da população que não utiliza as mídias sociais digitais.

Portanto, é pensando na diversidade de públicos conectados e não conectados que a melhor estratégia é aquela que mescla o tradicional e o contemporâneo em relações públicas. Assim como a internet revolucionou a vida das pessoas, dos negócios e da política, ela também influenciou uma profissão que tem na comunicação seu principal instrumento de trabalho. A essência da atividade de relações públicas - o relacionamento entre organizações e públicos - continua a mesma. 0 que muda é a forma como o profissional de relações públicas vai investir nesses relacionamentos. Dessa forma, a contemporaneidade da atividade ocorre de acordo com o conjunto de atividades planejadas para que uma organização se relacione com seus públicos.

Encontramos aqui o papel do relações-públicas na atualidade, ou seja, é aquele profissional que planeja a comunicação para todos os públicos percebendo também o potencial da web quanto às possibilidades de interação com eles e de visibilidade para a marca.

Para Solis (2007a), rp 2.0 vai além das relações de blogueiros, wikis, redes sociais, blogs etc. Essas são meramente ferramentas utilizadas para possibilitar o diálogo. A interatividade da web, aliada à habilidade de transformar leitores em produtores de conteúdo, está forçando a evolução de relações públicas independentemente de ser 1.0, 2.0 ou 3.0. Portanto, a ideia é integrar o melhor de relações públicas com a tecnologia, o marketing e a web.

Brian Solis e Deirdre Breakenridge, (2009, p. xviii), em relação às mídias sociais, já diziam que as organizações estavam passando por uma das maiores transformações e poucas eram as empresas que se davam conta disso. Se, por um lado, a mídia social exigia ou demandava engajamento, por outro, nem todas as empresas acreditavam que esse era 0 caminho. Elas hesitavam e ainda hesitam por razões como medo, descrença, subestimação, falta de retorno financeiro e métricas, percepções errôneas ou a combinação de todos esses fatores.

Ainda no que tange à participação das empresas nas plataformas de mídias sociais digitais, os mesmos autores (Solis; Breakenridge, 2009, p. xix-xx) acreditam que o segredo é deixar fluir e encarar o caos. Deixar o público falar, mas participar. Para eles, somos apenas intersecções na grande rede da vida e dos negócios. Precisamos participar para ganhar atenção dos públicos e pares. A mídia social requer diálogo de um para um e uma abordagem que humaniza e personaliza as histórias com o propósito de alcançar um público específico e não mais utilizando o marketing de transmissão. Os autores (Solis; Breakenridge, 2009, p. 1) acreditam que a mídia social é a reinvenção das relações públicas, pois a web mudou tudo. As mídias sociais estão empoderando uma nova classe de vozes com autoridade que não podemos ignorar. Solis (2007b) 


\section{ANO 12 • NÚMERO $22 \cdot 1^{10}$ sem. 2015 - ORGANICOM \\ ESTRATÉGIAS DE RELAÇÕES PÚBLICAS PARA AS ORGANIZAÇÕES \\ EM TEMPOS DE MÍDIAS SOCIAIS DIGITAIS}

complementa que relações públicas 2.0 não é mídia social e mídia social não é web 2.0. São movimentos distintos que podem se complementar e inspirar um ao outro.

Eugenia Barrichello et al. (2013, p. 129) compreendem as práticas de relações públicas sob a ótica da ecologia das mídias, ou seja, quando fluxos comunicacionais são redimensionados e novas estratégias são empreendidas a fim de interagir com públicos cada vez mais conectados e predispostos a dialogar e a participar em múltiplas ambiências.

Nesse sentido, a atividade de relações públicas apresenta extrema relação com a web 2.0 desde que suas estratégias sejam repensadas com base nos diferentes meios de comunicação digitais que surgiram nessa última fase. Para Barrichello et al. (2013, p. 150), a essência de relações públicas também continua a mesma, porém a área se mostra reconfigurada, pois, agora, as ações estratégicas se veem diante de ambiências que oferecem a potencialidade de estabelecer práticas colaborativas, participativas e interativas, proporcionadas pelas mídias sociais digitais.

Identificamos a atividade de relações públicas nas webs 3.0 e 4.0 no momento em que retomamos as características dessas fases, como, por exemplo, os algoritmos e os apps. As empresas e seus públicos estão sujeitos à imposição dos algoritmos das plataformas de mídias sociais digitais. Isso significa que tais algoritmos antecedem a relação organização-públicos. Deve-se considerar, ainda, o investimento necessário para que determinada mensagem alcance um percentual significativo de pessoas. No que tange aos apps, já identificamos, em diversas empresas, propostas criativas de aplicativos voltados aos produtos e serviços da organização, bem como direcionados ao engajamento do público com a marca. Portanto, do ponto de vista da implementação de ações de relações públicas na web, podemos dizer que a atividade de relações públicas já está inserida e sujeita aos ambientes 3.0 e 4.0 .

Os diferentes cenários apresentados mostram que a atividade de relações públicas também evolui permeando as diferentes fases da web. É por esse motivo que acreditamos que as relações públicas na contemporaneidade estão fortemente relacionadas ao cenário digital, porém não se restringindo a ele.

\section{MODELOS DE COMUNICAÇÃO CONTEMPORÂNEOS}

Neste segundo tópico, discorremos sobre modelos de comunicação e relações públicas que caracterizam a prática da atividade ao longo de todas as fases da web. Bianca Dreyer (2014, p. 106) descreveu dez, dos quais selecionamos dois que mais se aproximam da gestão da comunicação em tempo de mídias sociais digitais.

O primeiro deles é de David Brain (2012) e se chama The media cloverleaf, que significa "trevo da mídia" em português, ou seja, um modelo de relacionamento do ecossistema de mídia. Brain aponta cinco grandes mudanças que devem ser consideradas antes de refletir sobre o modelo. São elas: (1) a explosão dos canais de mídia; (2) o mundo multitelas; (3) todas as empresas são empresas de mídia; (4) as histórias ${ }^{3}$ são sociais; e (5) as histórias duram para sempre agora.

Diante disso, o autor descreve o ecossistema de mídia mostrando que ele é formado por quatro tipos de mídia distintos, porém relacionados. São eles: (1) a mídia tradicional, de amplo alcance, representada pelos veículos impressos e eletrônicos, entre outros; (2) a mídia híbrida que, justamente por misturar diferentes mídias, já nasceu digital; ela apresenta algumas

3 No entendimento da Edelman, histórias se referem ao conteúdo e a narrativas sobre a marca. 
características específicas como a integração, o engajamento de diferentes formatos, imagens e conteúdo; e pode também se apresentar como versões digitais da mídia tradicional, em blogs que atuam como se fossem empresas de mídia, em plataformas digitais etc; (3) a mídia própria, aquela de propriedade de uma organização, de algum grupo ou indivíduo; os sites das marcas e os aplicativos são exemplos; e, por fim, (4) a mídia social, aquela que possibilita que qualquer pessoa consiga se relacionar, dialogar e contar suas histórias em tempo real, como, por exemplo, o Facebook.

No meio do trevo, o autor aponta quais são as novas possibilidades de acesso às mídias, à pesquisa e a todas as definições de conteúdo. Segundo ele,

nós devemos nos empenhar para estimular o contar histórias que criem movimento e que perpassem todos os tipos de mídia. Temos que nos assegurar de duas coisas: a primeira é que as histórias pessoais façam parte da nossa produção e a segunda, que conteúdo de alta qualidade (infográficos e vídeos curtos) possa ser encontrado e compartilhado para melhorar os resultados da busca (Brain, 2012). ${ }^{4}$

Portanto, segundo Brain, devemos utilizar a metáfora do trevo para sincronizar como, quando e onde a história deve ser contada. A Figura 1 apresenta o modelo.

Figura 1 - The media cloverleaf- o novo ecossistema da mídia.

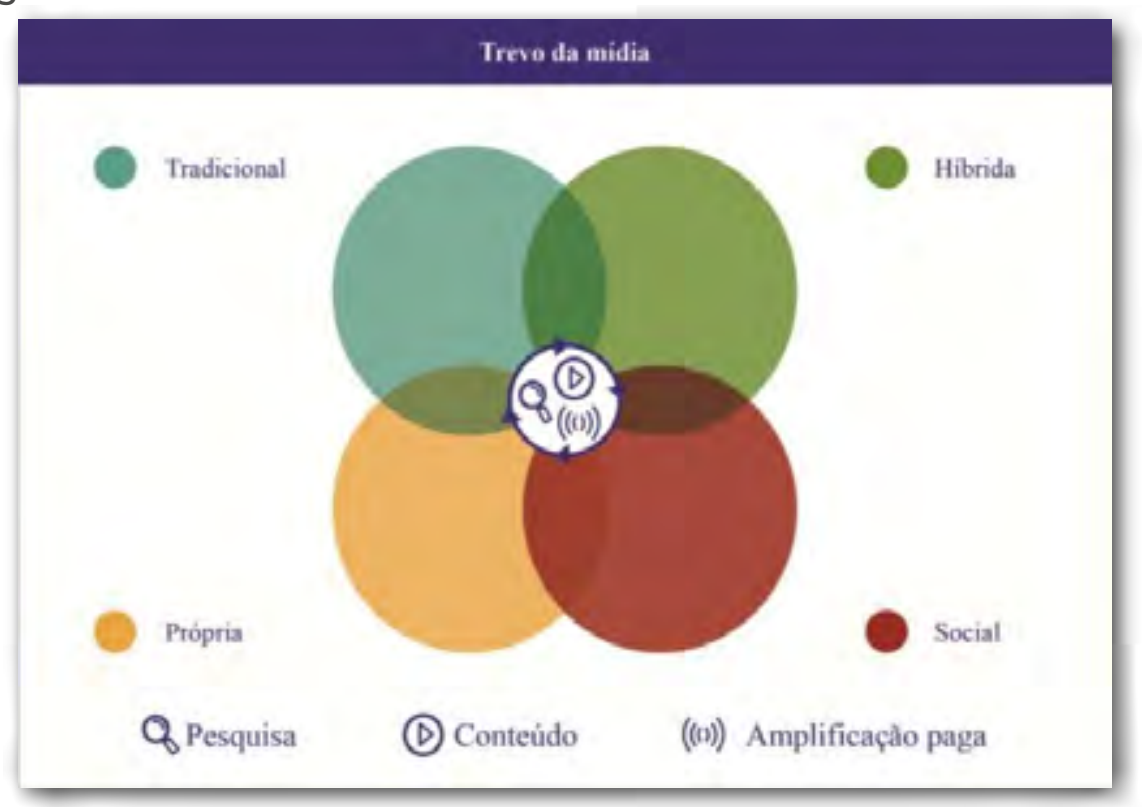

Arriscamos dizer que o modelo de filosofia da comunicação integrada (Kunsch, 2003) com inclusões da comunicação digital (Saad Corrêa, 2009) ${ }^{5}$, por exemplo, talvez possa constituir o passo que antecede o modelo do trevo. Acreditamos que, para chegar na parte central do ecossistema, é necessária, antes, a gestão da comunicação integrada digital na organização.

O segundo modelo, de Jenkins et al. (2013, p. 1), se chama "híbrido de circulação pervasiva". Os autores propõem um modelo onde uma combinação de forças determina como o conteúdo é compartilhado nas diferentes culturas de uma forma muito mais participativa e desordenada. Para compreendermos o modelo proposto por eles, é importante esclarecermos alguns conceitos centrais dos autores, como spreadable, spreadability e mídia pervasiva. Nesse sentido, Saad Corrêa (2013, p. 285) explica que,

a exemplo do que percebemos na língua portuguesa ao não encontrarmos a melhor tradução para 0 termo, 0 autor indica que 0 uso literal de spread (ou seja, untar, espalhar algo, muito relacionado a alimentos) é insuficiente para expressar sua proposta. Entretanto, manteve o termo como a expressão mais próxima de suas ideias. (...) Jenkins et al recorrem às ideias de Malcom Gladwell (numa típica ação de interação entre academia e mercado) que cunhou o termo aderência (stickiness) para expressarem 
a criação de conteúdos no meio digital que possuam a característica de atrair e fidelizar a audiência a ponto de esta se sentir motivada a compartilhar o conteúdo. Jenkins et al concluem: "para Gladwell, conteúdo aderente é aquele que as pessoas querem espalhar" (Jenkins et al, 2013, p. 4). Ao ocorrer tal espalhamento, entendem-se as inúmeras possibilidades de visibilidade destes conteúdos em diferentes espaços informativos, tornando-se pervasivo.

Por fim, pervasividade, para Jenkins et al (2013, p. 286) refere-se àqueles recursos técnicos que facilitam a circulação de determinados conteúdos em detrimento de outros (...) e às redes sociais que conectam as pessoas por meio do intercâmbio de bytes repletos de significado.

0 modelo híbrido de circulação é compreendido quando os autores (Jenkins et al, 2013, p. 2) o contrastam com o modelo de aderência, conforme resumimos nos sete itens que seguem:

(1) 0 modelo de aderência foca na contagem de membro; o modelo híbrido de circulação reconhece a importância das conexões sociais entre os indivíduos;

(2) 0 centro da aderência é a medição da audiência quantitativa; a circulação enfatiza a produção de conteúdo em formatos de fácil compartilhamento;

(3) Uma mentalidade aderente requer marcas para criar uma experiência centralizada oferecendo aos indivíduos maneiras limitadas e controladas para "personalizarem" conteúdo dentro de um formato de site; uma mentalidade circulável foca na criação de textos de mídia que várias audiências podem circular com diferentes propósitos;

(4) Sites aderentes geralmente incorporam jogos, testes e pesquisas para atrair e manter os interesses dos indivíduos; a lógica participativa da circulação leva as audiências a utilizarem o conteúdo de forma não prevista à medida que há adequação do material aos moldes de suas comunidades específicas;

(5) Uma vez que modelos de negócios aderentes são construídos a partir de dados demográficos, as audiências são geralmente construídas como um grupo de indivíduos passivos; a circulação, em contraste, valoriza as atividades dos membros da audiência e ajuda a criar interesse em marcas específicas ou franquias;

(6) A aderência retém a mentalidade de transmissão de comunicação de um para muitos, com canais oficiais autorizados que competem entre eles para chamarem a atenção da audiência; a circulação ou espalhamento parte do princípio de que tudo que vale a pena ser ouvido irá circular em todos os canais disponíveis, potencialmente levando as audiências de uma conscientização periférica a um engajamento ativo;

(7) Em um modelo de aderência, fica claro quem é o "produtor", o "comerciante" e a audiência - cada um desempenha um propósito separado e distinto; em um modelo de circulação ou de espalhamento, não há apenas um aumento na colaboração através desses papéis, mas, em alguns casos, os papéis chegam a se confundir.

Saad Corrêa (2013, p. 286) explica que a comparação do autor com relação aos conceitos de aderência - fortemente utilizado pela indústria digital para representar os desejos mercadológicos dos grandes players-e aquele de pervasividade, vinculado à movimentação natural e inerente da participação comunitária, pode gerar inferências inadequadas por parte de leitores desatentos. Essas inferências dizem respeito a uma possível visão errônea que o leitor poderá ter quanto a uma sobreposição de modelos, deixando a aderência de lado e direcionando a atenção apenas para a pervasividade. 
Para Jenkins et al (2013, p. 7), em um mundo de mídia espalhável, o que antes eram considerados assuntos apenas de "atendimento ao cliente" são, agora, também, cada vez mais, assuntos de "relações públicas", uma vez que os clientes espalham suas próprias histórias sobre as empresas.

Por fim, o modelo de circulação ou espalhamento de Jenkins et al trata de participação e de diálogo nas plataformas de mídias sociais digitais, ações que fazem parte de uma nova cultura, a cultura participativa. Estamos, portanto, frente a outro cenário da comunicação organizacional, no qual as empresas ficam praticamente sem alternativas no que tange à sua participação nas plataformas de mídias sociais digitais.

\section{ESTRATÉGIAS DE COMUNICAÇÃO EM TEMPOS DE MÍDIAS SOCIAIS DIGITAIS}

Neste terceiro tópico deste artigo, por fim, mostramos como a evolução da web bem como da atividade de relações públicas no ambiente digital e a descrição dos dois modelos de comunicação nos ajudaram a identificar indícios de quais são as estratégias indicadas para a gestão da comunicação em tempos de mídias sociais digitais.

0 profissional de relações públicas precisa compreender que a web 2.0 proporciona a interação e a existência de diversas plataformas de mídia social digital que promovem o diálogo em tempo real em um espaço virtual. As webs 3.0 e 4.0 aprimoram essa interação, influenciando na relação direta entre organizações e públicos devido à imposição dos algoritmos e do uso de aplicativos. Isso sem contar com o potencial de novos negócios que a fase 4.0 irá proporcionar, como a própria comunicação das coisas. Aqui importam a fase da web e suas características, mas importa mais ainda a atividade de relações públicas nesse contexto. Portanto, como vimos, de acordo com Solis e Breakenridge (2009), Terra (2010), Popova (2012) e Barrichello et al. (2013), as relações públicas digitais são aquelas que se aproximam mais da web 2.0 e que foram chamadas por esses autores de rp 2.0 devido à interação que só é factível a partir dessa fase. 0 conjunto desses autores também apontou as mídias sociais digitais como a melhor alternativa para o relacionamento entre organizações e públicos na atualidade, pois são espaços que oferecem práticas colaborativas, participativas e interativas.

Dreyer (2014, p. 154), após descrever os dez modelos de diferentes épocas, destacou que todos apresentam características inerentes à sua execução, como: 0 diálogo, a simetria, o relacionamento, a integração, a visibilidade e a interação.

Aos modelos mais contemporâneos, como aqueles que descrevemos anteriormente, somam-se outros elementos específicos do ambiente digital, como: o multiculturalismo, a cooperação, o digital integrado à comunicação tradicional e ao negócio, a adaptabilidade, a fluidez, a não-intermediação, a circulação, o hibridismo e o storytelling. Esses elementos são considerados fundantes de uma comunicação na sociedade digitalizada.

Embora seja apenas um levantamento inicial, sem uma análise aprofundada de cada uma das estratégias e dos elementos apontados, conseguimos adquirir uma ideia geral do que o profissional de relações-públicas deve ter em mente para elaborar um planejamento em tempos de mídias sociais digitais. Dessa forma, a última parte deste artigo apresentará indícios de uma proposta ainda incipiente de modelo de relações públicas na contemporaneidade.

A proposta de tal modelo compreende os estudos da teoria da midiatização como recorte teórico e a junção de três etapas voltadas à prática da atividade. Andreas Hepp propõe o conceito de "forças de moldagem da mídia" para integrar o melhor 


\section{ANO 12 • NÚMERO $22 \cdot 1^{10}$ sem. 2015 - ORGANICOM \\ ESTRATÉGIAS DE RELAÇÕES PÚBLICAS PARA AS ORGANIZAÇÕES EM TEMPOS DE MÍDIAS SOCIAIS DIGITAIS}

de duas tradições da teoria da midiatização: a institucional e a socioconstrutivista. De acordo com o autor (Hepp, 2014, p. 74), a tradição institucional está mais voltada para a mídia tradicional de massa e para a "lógica da mídia". Já a tradição socioconstrutivista está mais voltada às práticas de comunicação cotidianas, especialmente aquelas relacionadas à mídia digital e à comunicação pessoal, e enfoca a construção comunicativa em transformação da cultura e da sociedade.

A relação dessa teoria com a atividade de relações públicas vai ao encontro do que falamos anteriormente, ou seja, de que as relações públicas na contemporaneidade englobam um conjunto de diferentes formas de relacionamento com os públicos, sejam essas formas digitais ou não. Além disso, essa teoria encontra respaldo em Barrichello et al. (2013, p. 129), autores que compreendem as práticas de relações públicas sob a ótica da ecologia das mídias, como já citado também. Por fim, é uma teoria que engloba práticas cotidianas de comunicação, as quais consideramos fundamentais para a interação entre organização e públicos na atualidade.

A primeira etapa do modelo explica estratégia (Mintzberg et al., 2006,) e tem como principal objetivo relacionar a atividade de relações públicas ao processo de construção da estratégia, visto que, de acordo com Farias (2009, p. 52),

às relações públicas caberia a gestão dos relacionamentos e das ações comunicacionais da organização, mas a partir da visão de conjunto e de longo prazo, de uma participação estratégica no composto da organização, e não de uma posição operativa, com vistas à mera realização de tarefas. Assim, a gestão dos relacionamentos deve estar próxima e atrelada à estratégia da organização, e não apartada desta.

Para que possamos entender a atividade de relações públicas de forma estratégica e não com uma posição operacional no momento em que planejamos a comunicação das organizações, buscamos em Mintzberg et al (2006) a explicação de como construir uma estratégia diferenciando-a dos processos operacionais em uma organização. Justificamos o uso de Mintzberg et al. nesta etapa pelo fato de serem considerados autores clássicos do tema e também por estarmos tratando de uma primeira proposta de modelo de relações públicas na contemporaneidade.

Os autores (Mintzberg et al., 2006, p. 35-39) descrevem o processo de construção da estratégia por meio de quatro etapas que se complementam. Dessa forma, entende-se por estratégia a elaboração de um conjunto de atividades integradas, sustentáveis e de baixo custo. Por apresentarem um diferencial em relação aos concorrentes, essas atividades criam uma posição de valor para a empresa. Saber escolher o que não fazer também faz parte da estratégia.

A segunda etapa do modelo que estamos propondo é composta por uma série de atividades externas à organização, entre elas a pesquisa, a análise da concorrência, a análise de dados dos públicos (big data), principalmente nas mais diversas plataformas de mídias sociais digitais.

A terceira etapa do modelo se refere às questões internas, como a escolha dos temas que serão trabalhados, do conteúdo, das ações que serão desenvolvidas, da escolha de formas de relacionamento, como: storytelling, interação em tempo real, diálogo de uma para um, não-intermediação, circulação, hibridismo, entre outros. Essa etapa deve ser pensada totalmente em sintonia com a missão, a visão e, principalmente, os valores da organização.

Dessa forma, temos que a etapa um é a primeira e também a última etapa do modelo, pois ela é necessária, em um primeiro momento (etapa 1A da figura 2), para a compreensão do processo de estratégia, ou seja, para que o profissional de relações públicas identifique como ele pode planejar a atividade da área estrategicamente. E, em um segundo momento (etapa 1B da 


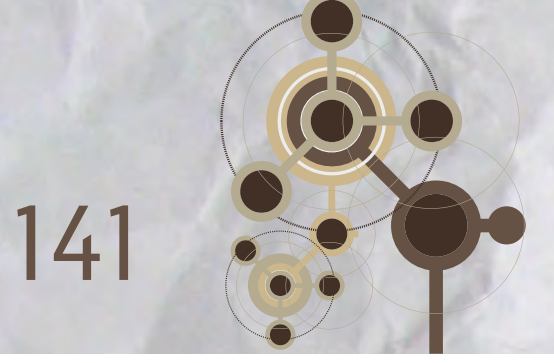

figura 2), para sua implementação após as etapas dois e três, respectivamente. 0 exemplo descrito, embora abrangente e sem aprofundamento de informações, é apenas uma das possibilidades para se pensar estrategicamente o relacionamento com os públicos. Nele, distribuímos cada conjunto de atividades em cada um dos quatro diferentes tipos de mídias, como descrito no modelo de Brain (2012) anteriormente. No entanto, podemos pensar no mesmo desenho estratégico para diferentes plataformas digitais como, por exemplo, substituir os quatro tipos de mídia por plataformas específicas, como Facebook, Twitter, Instagram e WhatsApp. 0 mais importante é entender que as atividades devem procurar ser, de alguma maneira, diferentes das atividades dos concorrentes (informação obtida na etapa 2, ou seja, saber o que o concorrente tem feito para poder fazer diferente), integradas e de longo prazo para criar, transmitir e fazer durar um valor empresarial que, posteriormente, se bem trabalhado pelos profissionais de relações públicas, poderá refletir em uma boa imagem e reputação empresarial. A Figura 2 representa o modelo:

Figura 2 - Proposta de modelo de relações públicas na contemporaneidade

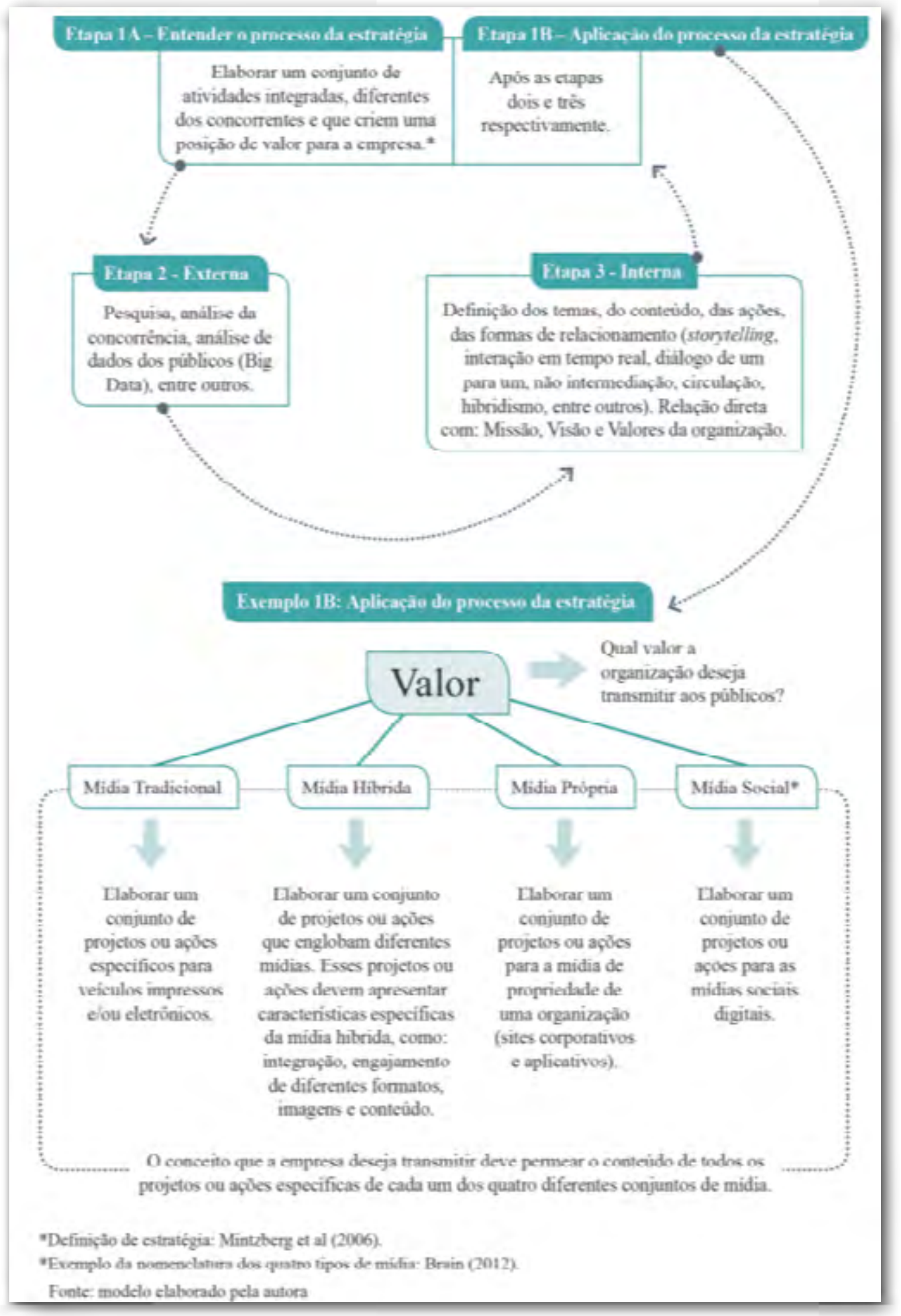

Finalmente, com o objetivo de retomar os principais aspectos que foram tratados neste artigo, apresentamos a Figura 3. 


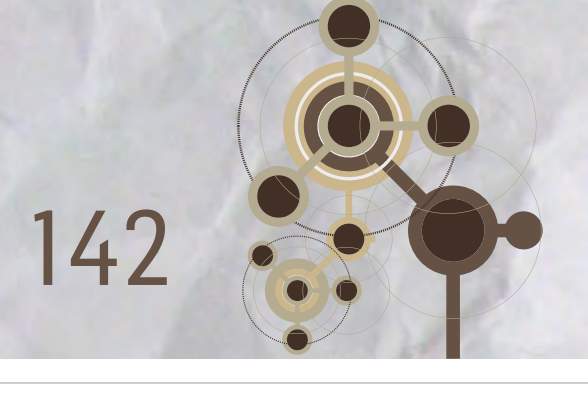

ANO $12 \cdot$ NÚMERO $22 \cdot 11^{\circ}$ sem. $2015 \cdot$ ORGANICOM

ESTRATÉGIAS DE RELAÇÕES PÚBLICAS PARA AS ORGANIZAÇÕES

EM TEMPOS DE MÍDIAS SOCIAIS DIGITAIS

Figura 3 - 0 percurso para entendermos as relações públicas digitais

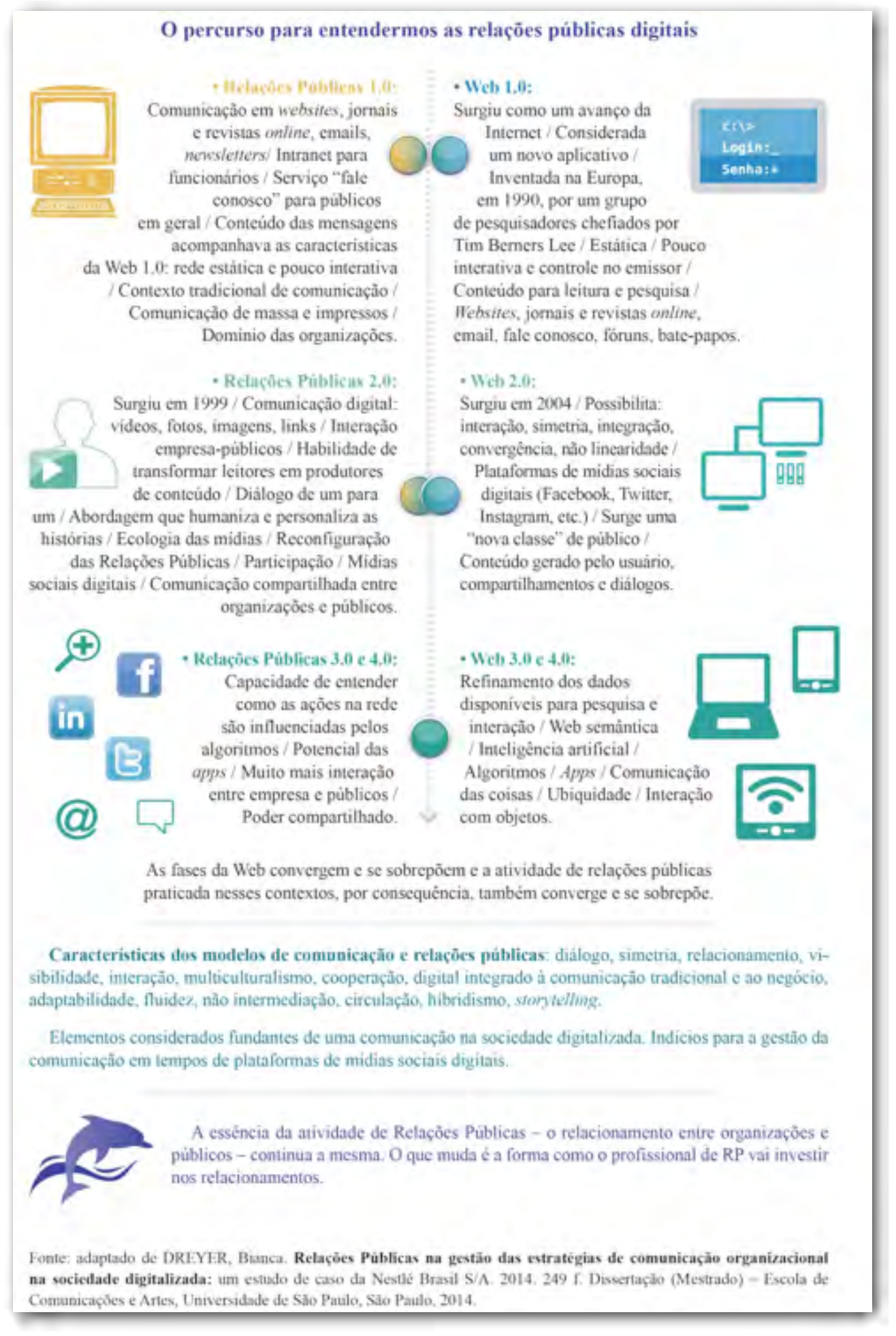

\section{CONSIDERAÇÕES FINAIS}

Este artigo teve como objetivo apresentar as relações públicas no contexto digital. Para isso, mostrou a evolução de quatro fases da web e a atividade de relações públicas em cada uma dessas fases. Vimos que a web 1.0 era considerada estática e a participação do usuário era praticamente entre ele e seu conteúdo, sendo a pesquisa um aspecto importante nessa etapa. A web 2.0 trouxe a interação entre pessoas e conteúdos, sendo as plataformas de mídias sociais digitais as grandes novidades dessa época. Já a web 3.0 aprimora profundamente as eras anteriores, proporcionando um refinamento dos dados disponíveis para pesquisa e interação, sendo a web semântica um dos pontos centrais dessa fase junto aos algoritmos e aos apps. Por fim, a web 4.0 parece ser uma revolução de tudo aquilo que vimos até então. No entanto, embora cada fase da web apresente suas características marcantes, tais fases não são exatamente cronológicas. Elas convergem e se sobrepõem. Portanto, a atividade de relações públicas praticada nesses contextos também converge e se sobrepõe. 
Nesse sentido, as relações públicas permeiam as diferentes fases da web de acordo com a cultura, a missão, os valores, 0 segmento, o porte e a estrutura de comunicação de cada empresa. Algumas organizações se mostram mais contemporâneas e ousadas quanto às práticas de comunicação na atualidade e outras mais cautelosas e até mesmo inseguras para ações no ambiente digital. No entanto, as relações públicas consideradas digitais se encontram na fase 2.0 da web, por isso são denominadas por alguns autores como rp 2.0. Essa denominação se deve à interação proporcionada pelas plataformas de mídias sociais digitais. Arriscamos dizer, porém, que, embora seja evidente a inerência dessa atividade com as TICs, as relações públicas não devem ser vinculadas a nenhuma fase específica da web. Isso se deve ao fato de tais fases evoluírem rapidamente e a essência de relações públicas permanecer a mesma. 0 que evolui na atividade de relações públicas é o conjunto de estratégias que deve ser desenvolvido para que uma organização se relacione com seus públicos, na contemporaneidade.

Para exemplificar as relações públicas no contexto digital, foram descritos também dois modelos de comunicação contemporâneos. Ambos apresentaram estratégias que podem ser usadas pelas empresas de acordo com seus objetivos de relacionamento com os públicos e o planejamento da comunicação.

Finalmente, o percurso até aqui nos forneceu indícios de quais são os elementos e as estratégias indicadas para a gestão da comunicação em tempos de mídias sociais digitais. Esse levantamento contribuiu para a elaboração de uma proposta ainda incipiente de modelo de relações públicas na contemporaneidade, conforme descrito na Figura 2.

\section{REFERÊNCIAS}

BARICHELLO et al. Estendendo as práticas de relações públicas sob a perspectiva teórica da ecologia das mídias. In: RUBLESCKI, Anelise; BARICHELLO, Eugenia Mariano da Rocha (Org.). Ecologia da mídia. Santa Maria: Facos-UFSM, 2013.

BRAIN, David. 2012. Transmedia storytelling and the media cloverleaf. Disponível em: <http://www.edelman.com/post/ trans-media-storytelling-and-the-media-cloverleaf-3/>. Acesso em: 15 abr. 2014.

CASTELLS, Manuel. A sociedade em rede. São Paulo: Paz e Terra, 2011.

CORREAA, Elizabeth Saad. Uma reconfiguração cultural possível e viável. MATRIZes, São Paulo, Programa de Pós-Graduação em Ciências da Comunicação da Escola de Comunicações e Artes da Universidade de São Paulo (ECA-USP), a. 7, n. 1, p. 283289, 1. sem. 2013.

Estratégias 2.0 para as mídias digitais. internet, informação e comunicação. 2a ed.. São Paulo: Editora Senac, 2003.

Comunicação digital e novas mídias institucionais. In: KUNSCH, Maegarida M. Krohling (Org.). Comunicação organizacional. Vol. 1. Histórico, fundamentos e processos. São Paulo: Saraiva, 2009.

CORREAA, Elizabeth Saad; BERTOCCHI, Daniela. A cena cibercultural do jornalismo contemporâneo: web semântica, algoritmos, aplicativos e curadoria. MATRIZes, São Paulo, Programa de Pós-Graduação em Ciências da Comunicação da Escola de Comunicações e Artes da Universidade de São Paulo (ECA-USP), a., n. 2, p. 123-144, jan./jun. 2012.

DREYER, Bianca. Relações públicas na gestão das estratégias de comunicação organizacional na sociedade digitalizada: um estudo de caso da Nestlé Brasil S/A. 2014. 249 f. Dissertação (Mestrado em Ciências da Comunicação) - Escola de Comunicações e Artes da Universidade de São Paulo (ECA-USP), São Paulo, 2014. 
FARIAS, Luiz Alberto de. 0 campo acadêmico do ensino e da pesquisa em comunicação organizacional e relações públicas no Brasil. In: KUNSCH, Margarida M. Krohling (Org.). Comunicação organizacional. Vol. 1. Histórico, fundamentos e processos. São Paulo: Saraiva, 2009.

HEPP, Andreas. As configurações comunicativas de mundo midiatizados: pesquisa da midiatização na era da "mediação de tudo". MATRIZes, São Paulo, Programa de Pós-Graduação em Ciências da Comunicação da Escola de Comunicações e Artes da Universidade de São Paulo (ECA-USP), v. 8, n. 1, p. 45-64, 2014.

JENKINS, Henry. Cultura da convergência. São Paulo: Aleph, 2009.

JENKINS, Henry; FORD, Sam; GREEN, Joshua. Spreadable media: creating value and meaning in a networked culture. New York: New York University Press, 2013.

KUNSCH, Margarida M. Krohling. Planejamento de relações públicas na comunicação integrada. 4. ed. - rev., atual. e ampl. São Paulo: Summus, 2003.

LEMOS, André. A comunicação das coisas: teoria ator-rede e cibercultura. São Paulo: Annablume, 2014.

MINTZBERG et al. O processo da estratégia: conceitos, contextos e casos selecionados. 4. ed. Porto Alegre: Bookman, 2006. POPOVA,Diana.CanPR2.0beexplained?2012.Disponívelem:<http://research.bfu.bg:8080/jspui/bitstream/123456789/366/1/ BFU_2012_T_XXVII_\%20Popova.pdf>. Acesso em: 15 mar. 2014.

SANTAELLA, Lucia. A ecologia pluralista da comunicação: conectividade, mobilidade, ubiquidade. São Paulo: Paulus, 2010.

SOLIS, Brian. PRWeek claims industry enters age of PR 3.0. They couldn't be more wrong. 2007a. Disponível em: <http:// www.briansolis.com/2007/04/prweek-claims-industry-enters-age-of-pr/>. Acesso em: 20 mar. 2014.

SOLIS, Brian. PR 2.0 is not web 2.0. 2007b. Disponível em: <http://www.briansolis.com/2007/02/pr-20-is-not-web-20/>. Acesso em: 20 mar. 2014.

SOLIS, Brian; BREAKENRIDGE, Deirdre. Putting the public back in public relations: how social media is reinventing the aging business of PR. Upper Saddle River, NJ: Pearson Education, Inc. Publishing as FT Press, 2009.

TERRA, Carolina F. Usuário-mídia: a relação entre a comunicação organizacional e o conteúdo gerado pelo internauta nas mídias sociais. Tese (Doutorado em Ciências da Comunicação) - Escola de Comunicações e Artes da Universidade de São Paulo, São Paulo, 2010.

WIKIPÉDIA. web 1.0 Disponível em: <http://pt.wikipedia.org/wiki/World_Wide_web\#web_1.0>. Acesso em: 22 mar. 2014.

Artigo recebido em 16.03.2015 e aprovado em 01.06.2015. 